\title{
Comme du sang délayé
}

\section{Claude Simon}

\section{OpenEdition}

Journals

Édition électronique

URL : http://journals.openedition.org/ccs/667

DOI : $10.4000 /$ ccs. 667

ISSN : 2558-782X

\section{Éditeur :}

Presses universitaires de Rennes, Association des lecteurs de Claude Simon

\section{Édition imprimée}

Date de publication : 31 décembre 2010

Pagination : 19-22

ISBN : 9782354120771

ISSN : 1774-9425

\section{Référence électronique}

Claude Simon, «Comme du sang délayé », Cahiers Claude Simon [En ligne], 6 | 2010, mis en ligne le 21 septembre 2017, consulté le 15 septembre 2020. URL : http://journals.openedition.org/ccs/667 


\section{Claude Simon COMME DU SANG DÉLAYÉ}

Ce nom (Frascati) qui suscitait en moi, d'abord sans doute par l'évocation de confus souvenirs de musées, puis par une suite d'associations d'idées et de sensations, des visions à la fois agrestes (bruissantes frondaisons lentement balancées, fontaines, cascades) et voluptueuses (ces dernières dues peut-être à la façon dont se combinaient en un seul les deux mots : frasque - pas si loin de fiasque - et Chianti), qui revenait sans cesse dans les conversations des " anciens ", évoqué comme un "lieu » quelque peu fabuleux, légendaire, et où pendant longtemps je ne pus aller (je ne sais trop pour quelles raisons : d'abord, au début, à cause du règlement qui, pendant le premier mois de service, consignait les jeunes soldats au quartier, puis, lorsque nous fûmes autorisés à sortir, tout simplement je crois bien par le manque d'occasion (aucun d'entre nous n'étant lié d'amitié avec un " ancien " qui nous eût entraîné ou plutôt introduit) et aussi d'envie (nous doutant vaguement je suppose du genre de distractions que pouvait présenter un bastringue de garnison dans l'Est, de sorte que sans même nous être concertés nous meublions nos sorties du dimanche par une séance de cinéma suivie d'un dîner au restaurant avant de rentrer tout droit au quartier sans qu'il nous vînt même à l'idée pendant longtemps de solliciter une permission de minuit). J'y pénétrai pour la première fois un jour de mai, poussé sans doute, en dépit de nos préventions - et non seulement préventions, mais la quasi-certitude de voir s'écrouler ce qui avait été pendant plusieurs mois, malgré notre peu d'illusions, comme une sorte de symbole abstrait sur lequel nos appétits de plaisir et de débauche pouvaient se cristalliser - sans doute poussés, donc, 
par la curiosité, ou simplement l'ennui ceci s'ajoutant au fait que l'endroit, se trouvant légèrement en dehors de la ville, sur la route de Nancy, constituait par une belle journée un but de promenade, - ce nom d'ailleurs n'étant pas à proprement dire, comme je l'avais cru, celui de l'établissement (bal, guinguette) dont le patron aurait pompeusement paré sa maison mais, par un de ces facétieux hasards de la toponymie, celui du lieudit, la route à cet endroit entamant l'ascension d'une colline dont la dénomination était toujours et qui sait pourquoi celle de Frascati (appellation à la consonance d'autant plus ambiguë que pendant la guerre de 14-18 le front avait été pendant un certain temps arrêté sur une ligne dont la colline avait constitué l'un des principaux objectifs, lieu donc de combats sans doute assez sanglants puisqu'à son sommet, un peu au-dessous de l'endroit où la route se mettait à descendre, avait été élevé une sorte d'obélisque commémoratif, ceci ajoutant encore à la résonance de ce nom hybride (dans " Frascati » il y avait aussi " fracas »), de sorte qu'une autre image - ou si l'on préfère une autre "harmonique " - venait se superposer aux premières évocations : image du genre Épinal cette fois et quelque peu stéréotypée où (sans doute à cause de la consonance italienne du mot) je voyais, au milieu des éclatements d'obus en forme d'aigrettes rouges et jaunes se dessiner vaguement les silhouettes d'officiers l'épée haute et de soldats chargeant à la baïonnette dans des uniformes de zouaves pontificaux et non de combattants de 14 .

l'endroit du reste ne m'étant plus à ce moment-là étranger car nous y étions passés plusieurs fois au cours d'exercices ou de manoeuvres, de sorte que nous en connaissions l'aspect extérieur (assez peu engageant comme on pouvait s'y attendre : une de ces maisons sans époque définie placées au bord des routes peu après les sorties des villes, c'est-à-dire mi-citadines et mi-campagnardes (et, à vrai dire, plus campagnardes que citadines), tantôt transformées en postes à essence ou en garage, avec leur façade décrépie, leurs panneaux-réclame aux couleurs criardes et trop neuves, un appentis couvert de tôle ondulée appuyé contre l'un des vieux murs et abritant quelques voitures ou de ces camionnettes déglinguées qui servent au transport des bestiaux, dessous lesquelles s'extrait au coup de klaxon de l'automobiliste un type en combinaison maculée, au visage, aux mains et à la démarche de paysan qui s'avance en traînant lentement 
les pieds (chaussés de pantoufles marron à carreaux s'il fait beau, de bottes de caoutchouc noires s'il pleut), maussade et renfrogné, - ou encore transformées, comme là, en guinguette, une tonnelle de cornières rouillées sous laquelle se rouillent quelques tables et des chaises autrefois peintes en vert remplaçant l'appentis de tôle ondulée tandis que quelques caisses de fusains ou de troènes sont alignées devant la façade sur laquelle des réclames de boissons (Bière "La Meuse », Suze " apéritif à la gentiane », Byrrh) remplacent la publicité pour des marques d'huiles ou de pneus, la porte aux vieilles marches ouvrant sur une vaste salle froide nue aux murs d'une violente couleur orange et ornés de longues glaces sans cadre sur les bords desquelles sont peintes à la main et à l'huile (la couleur épaisse, pâteuse et maladroite) de naïves guirlandes de roses ou de camélias.

je ne me rappelle plus s'il y avait des chaises ou simplement des bancs autour des simples tables de bois recouvertes d'une affreuse peinture marron qui entouraient l'espace laissé libre au centre de la grande salle : non pas une piste cirée, brillante mais un plancher de bois raboté lavé à l'eau de Javel et à la sciure de bois, arrosé comme les chambrées de casernes des mêmes astragales en forme de huit baveux sombres et humides sur lesquels tournoyaient les lourds godillots à clous des artilleurs avec leurs éperons massifs leurs houseaux noirs leurs uniformes imprégnés de cette tenace et légère odeur de crottin qui se mêlait aux parfums bon marché et entêtants des bonniches aux visages ingrats malingres ou joufflus aux corsages blancs ou roses aux jupes de brillante soie noire et dont émanait on ne savait quoi d'à la fois violent, morne et obscène : les permanentes crêpelées et laineuses de cheveux non pas blonds mais plutôt couleur d'étoupe, mouillés de sueur, au-dessus des nuques grasses et blanches, l'espèce d'innocence brutale de cette sorte de parade sauvage qui se déroulait aux sons d'une musique sirupeuse se traduisant dans l'esprit en termes violents crus comme cette vieille chanson qui parle de c... barbu, c'était cela : pouvant, croyant en quelque sorte les voir sous les jupes virevoltantes, crépus bouche bête verticale et béante mangée de poils mouillés pendant bêtes en boucs faunesques entre les molles et livides cuisses tandis que continuaient à tourner sur le plancher grisâtre les bonniches soyeuses et leurs rêches toisons enlacées aux uniformes bleu-ciel des artilleurs dans un sillage de relents d'écurie, leurs tintillants éperons, leurs cols aux écussons d'un 
rouge clair, comme du sang délayé, sur lesquels s'inscrivaient en noir les deux chiffres du numéro de leur régiment.

Texte reproduit avec l'aimable autorisation de Réa Simon 